\title{
Assessment of Average Tracer Concentration Approach for Flow Rate Measurement and Field Calibration
}

\author{
P. Sidauruk ${ }^{*}$, Satrio and E.R. Pujiindiyati \\ Center for Isotopes and Radiaton Application, National Nuclear Energy Agency \\ Jl. Lebak Bulus Raya No. 49 Jakarta 12070, Indonesia
}

\section{ARTICLE INFO}

\section{Article history:}

Received 03 June 2015

Received in revised form 06 July 2015

Accepted 08 July 2015

Keywords:

Tracer method

Flow rate

Open channel flow

Tritium

Rhodamine WT

\begin{abstract}
A B S T R A C T
Tracer method is one of the methods available for open channel flow rate measurements such as in irrigation canals. Average tracer concentration approach is an instantaneous injection method that based on the average tracer concentrations value at the sampling point. If the procedures are correct and scientific considerations are justified, tracer method will give relatively high accuracy of measurements. The accuracy of the average tracer concentration approach has been assessed both in laboratory and field. The results of accuracy tests of open channel flow that has been conducted at the Center for Application Isotopes and Radiation Laboratory-BATAN showed that the accuracy level of average concentrations approach method was higher than $90 \%$ compared to the true value (volumetric flow rate). The accuracy of average tracer concentration approach was also assessed during the application of the method to measure flow rate of Mrican irrigation canals as an effort to perform field calibration of existing weirs. Both average tracer concentration approach and weirs can predict the trend of the flow correctly. However, it was observed that flow discrepancies between weirs measurement and average tracer concentration approach predictions were as high as $27 \%$. The discrepancies might be due to the downgrading performances of the weirs because of previous floods and high sediment contents of the flow.
\end{abstract}

(c) 2015 Atom Indonesia. All rights reserved

\section{INTRODUCTION}

There are several methods available for open channel flow rate measurements such as tracer dilution, velocity-area, and hydraulic structures methods [1]. Due to its simplicity, low in cost and high accuracy, hydraulic structures methods such as weirs and flumes are the most commonly used as primary measurement devices in open channel flow. Although the accuracy of hydraulic structures based methods is relatively good, however, regular maintenance and field calibration are needed to update the relation between water level and water discharge. Tracer and velocity-area methods, on the other hand, are commonly used for calibration purposes or for measuring flow rate where primary

\footnotetext{
* Corresponding author.

E-mail address: pastons@batan.go.id

DOI: http://dx.doi.org/10.17146/aij.2015.416
}

measurement devices are not available. Tazioli (2011) have reported the comparison of current meter and tracer methods on small tributary flow rate measurements [2]. It was reported that the discrepancy of current meter with actual discharge was increased as the flow increased.

Tracer method has been used for many applications for the last several decades, i.e., Sidauruk, Cheng, and Ouazar (1998) developed inverse numerical modeling for predicting contaminant transport parameters [3], Kinyanjui, Tsombe, Kwanza, and Gaterere (2011) investigated the effects of the depth, channel radius, slope of the channel, lateral inflow, manning coefficient in open channel flow using finite difference approximation method [4], numerical approximation method was also applied by Kinyanjui, et al., (2011) to solve highly nonlinear the Saint-Venant partial differential equation in circular cross-section open channel flow 
[5], and Van Genutchen, et.al, (2013) developed transient and decay exact analytical solutions for contaminant transport in rivers [6]. Lee, Chung, and Park applied tracer method to verify flow rate of feed water in close conduits [7]. All of previous studies were based on breakthrough curves but sometimes those may not be very practical especially in field measurements. Current study is focusing on a more practical method, average tracer concentration approach.

Tracer is a substance that is soluble in water, detectable, and can be measured at different concentrations. In general, tracers can be divided in to 3 types, i.e., chemical, dyes, and radioactive tracers [8-9]. The tracer types will be chosen based on several factors such as availability of the tracers, the cost of the tracers, equipment availability, regulation, estimated flow rate to be measured, effect on the environment and human health, and the location of the study. In Indonesia, several studies using tracer method have been conducted such as to investigate the interconnections of monitoring wells in dam system [10].

The objectives of the current study are to assess the accuracy of average tracer concentrations approach in laboratory and to apply average tracer concentrations approach to measure open channel flow and to calibrate existing flow measurement.

\section{THEORY}

Tracer method can be divided in to 2 principles, namely, a tracer method based on travel time and a tracer method based on tracer dilution. The tracer method that based on travel time is normally used in closed conduit or in open channel that is very regular in profile.

Tracer dilution method that is discussed in this paper is tracer dilution method that based on instantaneous sources (Fig. 1). This method is based on conservation of injected tracer mass. The method is commonly applied by injecting appropriate amount of tracer into flowing water and let it to mix, dilute, and flow with the water for certain of time before sampled (detected) at the downstream [11].

For conservative tracer, if transversal and depth variations can be neglected then tracer distribution in longitudinal direction as a function of time analytically can be written as $[8,12-14]$ :

$$
C(x, t)=\frac{M}{2 A \sqrt{\pi D_{x} t}} e^{\left(\frac{-\left(x-v_{x} t\right)^{2}}{4 D_{x} t}\right)}
$$

In which $M$ is mass of injected tracer and $A$ is the cross section of the river or sewer, where $v_{x}$ and $D_{x}$ are velocity and hydrodynamic dispersion coefficients in longitudinal direction, respectively. This analytical equation is still valid for radioactive tracer if the half-life of the tracer is much longer than duration of the experiment. As an example tritium tracer used in this study was assumed to be conservative tracer because of its half-life 12.32 years was extremely higher compared to the duration of experiment which was only about 30 minutes.

Analytical solution (1) can be seen as normal probability density function with mean $=v_{x} t$ and variance $\left(\sigma^{2}\right)=4 D_{x} t$.

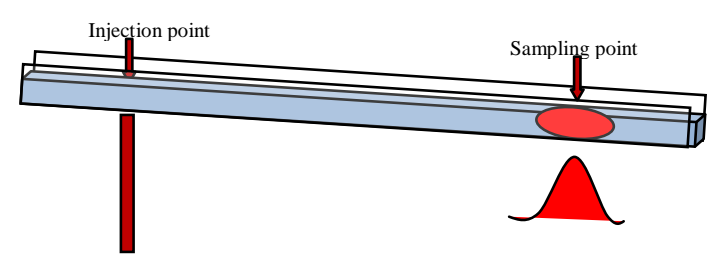

Fig. 1. Injection and sampling points and the corresponding breakthrough curves.

The curve of injected tracer concentration as a function of time at certain point is normally called breakthrough curve. If well mixed has been achieved, the shape of this curve is close to bell shape. Figure 2 shows typical breakthrough curves at 3 different points. While the peak of the breakthrough curve will be flatten as further downstream, the area of the curve, however, is conserved.

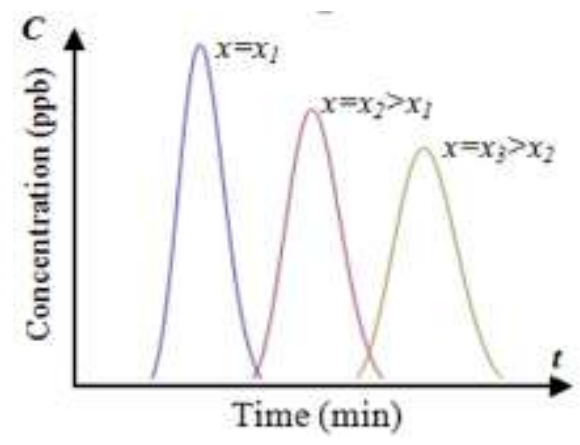

Fig. 2. Breakthrough curves at three different locations.

According to mass conservative law, the total mass of tracer observed at given location is equal to mass of injected tracer as can be written in the following formula:

$$
\begin{aligned}
& M=A v_{x} \rho \int_{0}^{\infty} C(t) d t=Q \rho \int_{0}^{\infty} C(t) d t \\
& Q=\frac{M}{\rho \int_{0}^{\infty} C(t) d t}=\frac{M}{\rho A_{c}}=\frac{S_{g} C_{i} V_{i}}{A_{c}}
\end{aligned}
$$


Where, $M$ is the mass of injected tracer, $A$ is the cross section of the channel at sampling point, $v_{x}$ is the velocity of the flowing water, $Q$ is the debit or flow rate, $\rho$ is density of the water, $V_{i}$ is the volume of injected tracer, $C_{i}$ is the concentration of injected tracer, $S_{g}$ is the specific gravity of injected tracer (in this study $S g$ was assumed to be 1 due to the fact that the tracer was diluted before injection), and $A_{c}$ is the area of breakthrough curve. Integration of equation (1) to find the area of breakthrough curve can't be done analytically because of unknown parameters such as coefficient of hydrodynamic dispersion. For this reason, the area of breakthrough curve will be found by numerical integration method. If the length of the base of breakthrough curve $\left(t_{f}-t_{0}\right)$ is discretized into $n$ subdivisions then approximation of the area of the breakthrough using Trapezoidal rule can be written as:

$$
\begin{aligned}
A_{c}= & \int_{0}^{\infty} C(t) d t=\int_{t_{0}}^{t_{f}} C(t) d t \approx \\
& \frac{t_{f}-t_{a}}{2 n}\left[C_{0}+2 C_{1}+\cdots+2 C_{n-1}+C_{n}\right]
\end{aligned}
$$

where $t_{0}$ is the time before the cloud of the concentration reaches the sampling point and $t_{f}$ is the time of the tracer cloud completely leaves the sampling point as sketched in Fig. 3 .

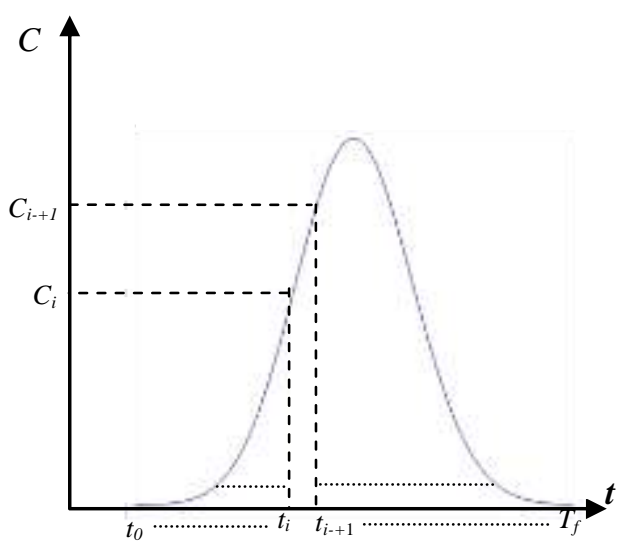

Fig. 3. Discretization of breakthrough curve at sampling point $x_{0}$.

For relatively small flow, tracer is normally diluted before the introduction of the tracer in to flowing water using equation (4).

$$
C_{i}=C_{t r} S_{g} \frac{V_{t r}}{V_{m}},
$$

where

$C_{i}=$ concentration of the tracer to be injected,

$C_{t r}=$ concentration of concentrated tracer, (for rhodamine WT, $C_{0}=20 \%=2 \times 10^{8} \mathrm{ppb}$ )
$S_{g}=$ specific gravity of concentrated tracer

( 1 for tritium and 1.19 for rhodamine WT),

$V_{t r}=$ volume of concentrated tracer,

$V_{m}=$ volume of diluted tracer $=V_{t r}+V_{w} \approx V_{w}$.

$V_{w}=$ volume of reference water.

\section{CALCULATION METHODS}

\section{Tracer used}

In this study, tritium and rhodamine WT were used as tracers.

Tritium $\left({ }^{3} \mathrm{H}\right)$ is one of hydrogen isotopes with atomic weight is 3 . Tritium is radioactive tracer that emits $\beta$-particles. This tracer was chosen because of its solubility in water in addition to the availability of tracer and liquid scintillation counter with high accuracy. Common unit for tritium radioactivity is $B q$ (Becquerel) or $C i$ (Currie) in which $1 C i=3.710^{10} \mathrm{~Bq}$. For low radioactivity of tritium, however, the radioactivity unit that commonly used is tritium unit (TU). One liter water of concentration of $1 \mathrm{TU}$ is equivalent to $0.12 \mathrm{~Bq}$ in radioactivity. Other characteristics of this tracer are [14-15]: half-life is 12. 32 years; average and maximum energies are 5.7 and $18.6 \mathrm{keV}$, respectively; specific activity in $\mathrm{T}_{2} \mathrm{O}$ is $2700 \mathrm{Ci} / \mathrm{g}$; annual limit intake (ALI) is $80 \mathrm{mCi}$; maximum permissible concentration $1 \times 10^{-3} \mu \mathrm{Ci} / \mathrm{ml}$.

Rhodamine WT is known also as orange or pink fluorescent with molecular formula and weight are $\left(\mathrm{C}_{29} \mathrm{H}_{29} \mathrm{~N}_{2} \mathrm{O}_{5} \mathrm{Na}_{2} \mathrm{Cl}\right)$ and 566, respectively. Rhodamine WT is available in the market as a $20 \%$ solution in water with specific gravity about 1.19. This tracer was choosen because of its high solubility in water, and very low photo-decomposition effect. Some other characteristics of rhodamine WT that make it a good tracer especially in the field measurements are given [16-17]. It can be detected in situ using portable fluorometer with low detection limit; at concentration greater than $25 \mathrm{ppb}$ can be detected visually; maximum permissible concentration in water tracing is $100 \mathrm{ppb}$; can be used to measure flow rate up to $\sim 85 \mathrm{~m}^{3} / \mathrm{sec}$.

\section{Average tracer concentration approach}

Average concentrations approach discussed in this study is based on the tracer dilution principle. The error of the estimation using trapezoidal rule given $n$ equation (3) is inversely proportional to the squared of the number of sub-intervals. Hence, to minimize the error, the number of subintervals 
(discrete samples) needs to be relatively large. However, collecting large number of samples in separate bottles and counting them individually are not very practical especially in field measurements due to time and space constraints. For this reason, the area of the breakthrough curve will be approximated using average concentration. If the counting is started before the tracer enters the sampling point and finished after the tracer completely leaves the sampling point then $C_{0}$ and $C_{n}$ can be neglected. Further if the number of discrete samples is large enough then $n-1 / n \approx 1$. Considering all of these assumptions, equation (3) can be simplified as:

$$
A_{C} \cong t_{e} \bar{C}
$$

Where $\bar{C}=\sum_{i=1}^{n} C_{i} / n$, and $t_{e}=t_{f}-t_{0}$ is the duration

of collection of samples. Therefore, the formula for flow rate given in equation (2) can be simplified to the following equation:

$$
Q=\frac{S_{g} C_{i} V_{i}}{t_{e} \bar{C}}
$$

In this approach, the samples are collected in a constant time interval $\Delta t$. The time interval $\Delta t$ depends on the size of the flume of the tracer and it is determined such that the number of collected samples has to be more than 20 samples. In this method, each collected sample is directly put into a bucket and at the end of the experiments the bucket that contains collected samples will be stirred to homogeneous mix to get average concentration $\bar{C}$.

\section{Accuracy test of tracer method using Tritium and Rhodamine WT}

The accuracy test for the tracer method was conducted at the Center for Application of Isotopes and Radiation-BATAN Laboratory, Jakarta. The tracer method was applied to measure steady flow with known flow rate. Flow rate for each experiment was firstly measured using conventional volumetric method that is by tapping water in a bucket with known volume, and the time $(t)$ to fill the bucket. The flow rate then was found by dividing the volume of the bucket with time $t$.
The collection of samples was started before cloud of the tracer reached the sampling point and ended after the cloud of the tracer completely left the sampling point. At each sample collection, 1 sample for tritium analysis and 1 sample for rhodamine WT analysis were collected. Although the focus of this study was to discuss average tracer concentration approach, however, in order to elaborate the performance of average tracer concentration approach thoroughly, the breakthrough curves method was also conducted. Hence, the collection of samples was divided in to two strategies namely collection of samples for breakthrough curves method and the collection of samples for average tracer concentration approach.

In this accuracy test, three experiments with different flow rates were conducted as given in Table 1.

Table 1. Volumetric flow rate of experiments

\begin{tabular}{ccc}
\hline No. & Experiment & Volumetric flow rate $\left(\mathrm{Q}_{\mathrm{vol}}\right) \mathrm{ml} / \mathrm{sec}$ \\
\hline 1 & Experiment-1 & 200.27 \\
2 & Experiment-2 & 253.91 \\
3 & Experiment-3 & 456.55 \\
\hline
\end{tabular}

For breakthrough curves method, the samples were collected in intervals 5, 3, and 2 seconds for experiments 1, 2, and 3, respectively. Each sample of about $20 \mathrm{ml}$ was placed at different bottle sample. All samples for tritium analysis were counted using liquid scintillation counter and all samples for rhodamine WT analysis were counted using portable fluorometer.

For average tracer concentrations approach, the samples were collected in an interval of two seconds for all three experiments. All collected samples at each experiment were placed in two buckets; one bucket was designated for tritium analysis samples and another bucket for rhodamine WT analysis samples. At the end of each experiment, the sample in the bucket was stirred to well mix and 1 sample from each bucket was collected and placed in a bottle of $20 \mathrm{ml}$. The sample for tritium analysis was counted using liquid scintillation counter and the sample for rhodamine WT was counted using portable fluorometer. The concentration of well mixed samples was labeled as $\bar{C}$. 


\section{Flow rate measurement and field calibration in open channel}

The field location of current study was in Brantas River. Brantas river is one of the longest rivers in East Java and it is used for all aspects that related to the rivers as irrigation, flood control, power generation, water supply, fishery, and recreation. Irrigation is one of the most important aspect of Brantas river. The water distributions need to be controlled especially during dry season. Many irrigation inlet systems have been built along Brantas river and one of those is Mrican irrigation inlet system which is located about $7 \mathrm{~km}$ north of the city of Kediri as given in Fig. 4. Mrican irrigation system has 2 canals one from each side of the rivers namely Left Mrican canal and Right Mrican canal. The two irrigation canals convey water from the intakes to about 30,000 ha paddy farm in the region. So far, the flow rate of the water is interpreted through the height of the water above the crest of the constructed weir at each canal.

The objectives are to measure the flow rate of Mrican irrigation canals using average tracer concentration approach and to probe the possibility of using this method as a field calibrator for current and future use for the existing constructed weirs at the irrigation canals.

For these objectives, three different flows for each canal were conducted. The three different flows are generated by adjusting the intake gates as in Table 2.

Table 2. Three different flows in Left and Right Mrican irrigation canals flow measurements

\begin{tabular}{cc}
\hline Case & \multicolumn{1}{c}{ Remarks } \\
\hline Case-1 & The intake gates is open normally \\
Case-2 & The intake gates is open to $\sim 50 \%$ of normal height \\
Case- 3 & The intake gates is open to $<50 \%$ of normal height \\
\hline
\end{tabular}

Before injecting the tracer into flowing water, several factors such as rough estimate of the flow, wet perimeter of the canal, detection limit of the fluorometer, injection point, and sampling point were determined. To speed up the process of dilution of tracer in to flowing water, it was important to choose injection point where the turbulence flow appears. The rough estimate of the flow was used to determine the amount of the tracer to be injected. The amount of injected tracer was calculated such that the expected observed average concentration was within detection limit of fluorometer. The sampling point was the point where lateral good mixing between tracer and water had been achieved. In this study, the length of good mixing was approximated using empirical formula introduced by Guizerix and Florkowski [18] as given below:

$$
L=10 \sqrt{\frac{b^{3}}{h}}
$$

where $b$ and $h$ were the width and average depth in meter of the canal, respectively. In determining the sampling point at the downstream, equation (7) was used as a first estimation and it was confirmed by visual observation in the field. For consistency purpose, the samples were taken at two different locations.

\section{RESULTS AND DISCUSSION}

\section{Accuracy test of tracer method using Tritium and Rhodamine WT}

Before the tracer was introduced into the flowing water, natural tracer concentrations (background concentrations) for both tritium and rhodamine WT were measured. During the accuracy tests, background concentrations for tritium and

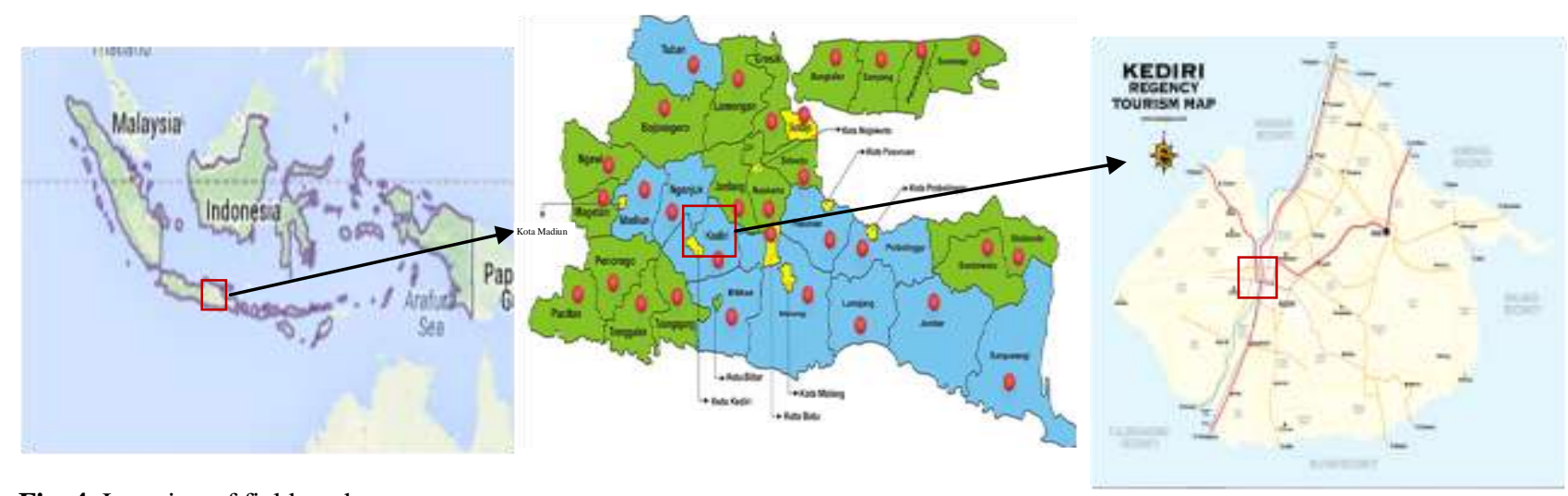

Fig. 4. Location of field study. 
rhodamine were relatively constant at about $3 \mathrm{TU}$, and $0.1 \mathrm{ppb}$, respectively. These background concentrations were later deducted from each measured concentrations. Both tritium and rhodamine WT tracers were injected simultaneously in to flowing water at the same location at the upstream of the channel. For all three experiments, the concentrations of injected tracers were 87000 $T U$ and $25600 p p b$ for tritium and rhodamine WT, respectively.

The breakthrough curves are presented in Figs. 5(a) and 5(b) for tritium and rhodamine WT tracers, respectively. The area of breakthrough curves, $A_{c}$, was calculated using equation (3) and flow rate, $Q$, was determined using equation (2). The details of inputs for all three experiments together with calculated breakthrough curves area and flow rates are presented in Table 3 for both tritium and rhodamine WT.

Table 3. Input and Results of accuracy test by breakthrough curve method

\begin{tabular}{ccccccc}
\hline & & & \multicolumn{2}{c}{ Tritium } & \multicolumn{2}{c}{ Rhodamine WT } \\
\cline { 4 - 7 } Exp. & $t_{e}$ & $V_{i}$ & \multicolumn{2}{c}{$C_{i}=87000 \mathrm{TU}$} & \multicolumn{2}{c}{$C_{i}=25600 \mathrm{ppb}$} \\
\hline & $\mathrm{sec}$ & $m l$ & $\begin{array}{c}A_{c} \\
T U-\mathrm{sec}\end{array}$ & $\begin{array}{c}Q \\
(\mathrm{ml} / \mathrm{sec}\end{array}$ & $\begin{array}{c}A_{c} \\
T U-\mathrm{sec}\end{array}$ & $\begin{array}{c}Q \\
(\mathrm{ml} / \mathrm{sec}\end{array}$ \\
\hline 1 & 66 & 50 & 26908.2 & 162.5 & 6268.6 & 204.2 \\
2 & 48 & 100 & 34657.5 & 253.3 & 9823.5 & 260.6 \\
3 & 36 & 160 & 30683.4 & 457.7 & 8500.0 & 481.9 \\
\hline
\end{tabular}

Note: $t_{e}$ is the duration of experiment and $V_{i}$ is the volume of the injected tracer
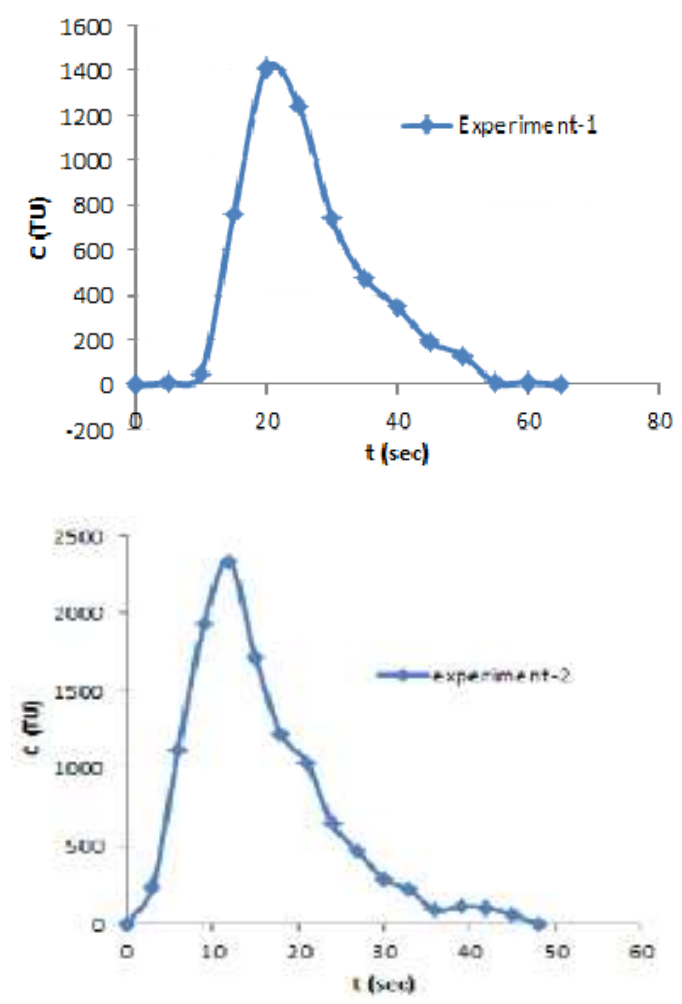

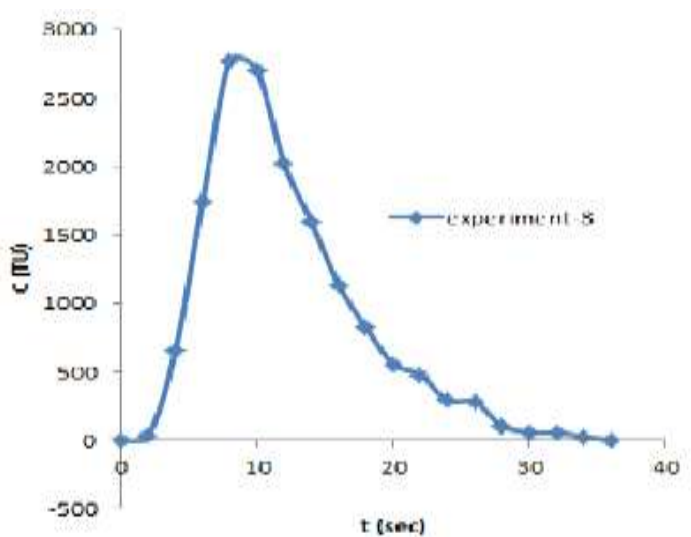

(a)

Fig. 5(a). Tritium breakthrough curves of experiment-1, 2, and 3 .
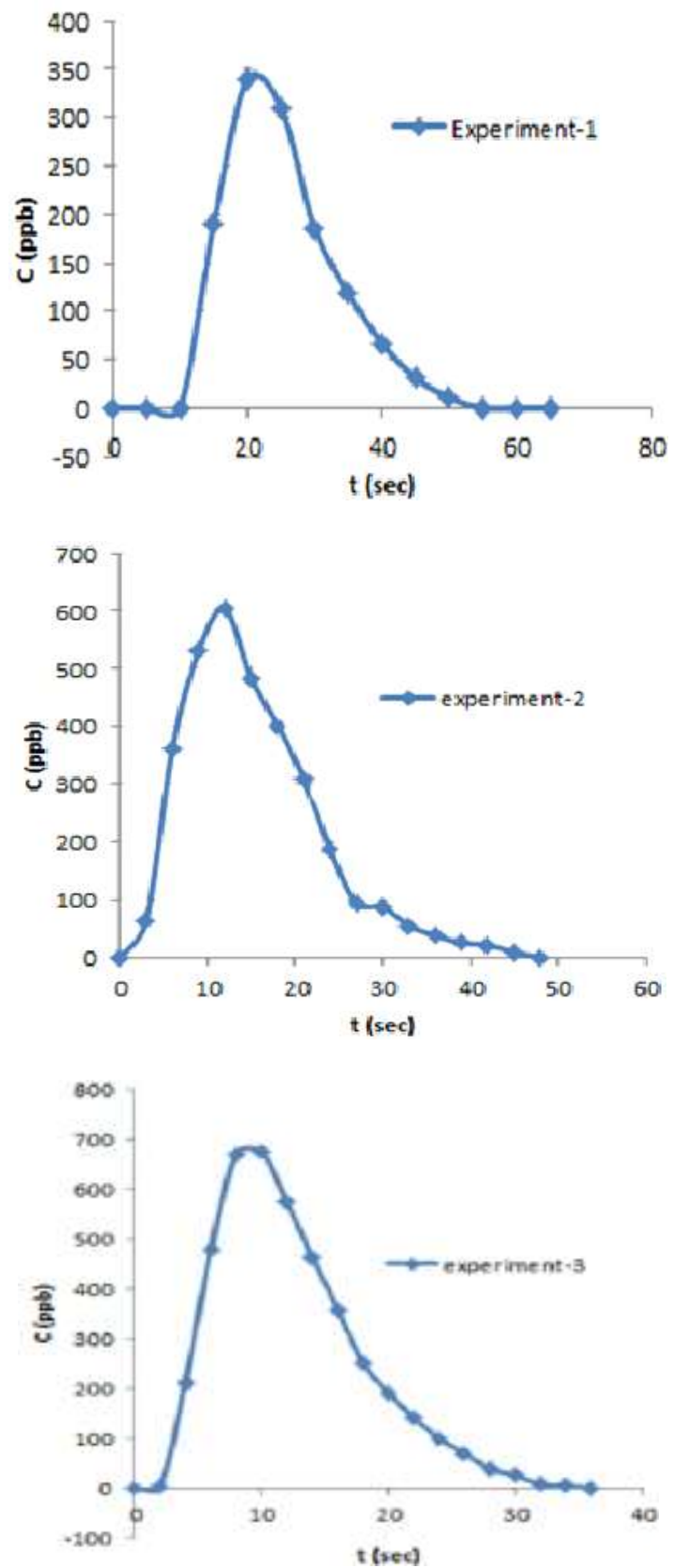

(b)

Fig. 5(b). Rhodamine WT breakthrough curves of experiment1,2 , and 3 . 
Table 4 shows flow rate $(Q)$ for average tracer concentration approach that was calculated using equation (6) together with input information.

Table 4. Input and Results of accuracy tests by average tracer concentration approach

\begin{tabular}{ccccccc}
\hline Exp. & $\begin{array}{c}t_{e} \\
(\mathrm{sec})\end{array}$ & $\begin{array}{c}V_{i} \\
(\mathrm{ml})\end{array}$ & \multicolumn{2}{c}{ Tritium } & \multicolumn{2}{c}{\begin{tabular}{c} 
Rhodamine WT \\
\cline { 4 - 7 }
\end{tabular}} \\
\cline { 4 - 7 } & & & $\bar{C}$ & $\begin{array}{c}Q \\
C_{i}=25600 \mathrm{ppb}\end{array}$ \\
\hline 1 & 66 & 50 & 313.4 & 198.1 & $\bar{C}$ & $\begin{array}{c}Q \\
(\mathrm{ml} / \mathrm{sec})\end{array}$ \\
2 & 48 & 100 & 610.8 & 266.1 & 205.0 & 201.2 \\
3 & 36 & 160 & 802.3 & 486.3 & 245.0 & 464.4 \\
\hline
\end{tabular}

Note: $t_{e}$ is the duration of experiment and $V_{i}$ is the volume of the injected tracer

Table 5(a). Flow rates comparison between break- through curves method and volumetric measurement

A. Breakthrough curves

\begin{tabular}{cccccc}
\hline \multirow{2}{*}{ Exp } & Volumetric & \multicolumn{2}{c}{ Tritium } & \multicolumn{2}{c}{ Rhodamine WT } \\
\cline { 2 - 6 } & $\begin{array}{c}\mathrm{Q} \\
(\mathrm{m} / \mathrm{sec})\end{array}$ & $\begin{array}{c}\mathrm{Q} \\
(\mathrm{m} / \mathrm{sec})\end{array}$ & $\begin{array}{c}\varepsilon \\
(\%)\end{array}$ & $\begin{array}{c}\mathrm{Q} \\
(\mathrm{m} / \mathrm{sec})\end{array}$ & $\begin{array}{c}\varepsilon \\
(\%)\end{array}$ \\
\hline 1 & 200.27 & 162.50 & 18.8 & 204.19 & 1.96 \\
2 & 253.91 & 253.27 & 0.25 & 260.60 & 2.63 \\
3 & 456.55 & 457.71 & 0.25 & 481.86 & 5.54 \\
\hline
\end{tabular}

Note: $\varepsilon$ is the relative error of breakthrough curves method with respect to volumetric in \%

Table 5(b). Flow rates comparison between average tracer concentration approach and volumetric measurement

B. Average tracer concentration approach

\begin{tabular}{cccccc}
\hline & Volumetric & \multicolumn{2}{c}{ Tritium } & \multicolumn{2}{c}{ Rhodamine WT } \\
Exp & $\begin{array}{c}\mathrm{Q} \\
(\mathrm{m} / \mathrm{sec})\end{array}$ & $\begin{array}{c}\mathrm{Q} \\
(\mathrm{m} / \mathrm{sec})\end{array}$ & $\begin{array}{c}\varepsilon \\
(\%)\end{array}$ & $\begin{array}{c}\mathrm{Q} \\
(\mathrm{m} / \mathrm{sec})\end{array}$ & $\begin{array}{c}\varepsilon \\
(\%)\end{array}$ \\
\hline 1 & 200.27 & 198.09 & 1.08 & 201.18 & $<0.01$ \\
2 & 253.91 & 266.13 & 4.81 & 260.16 & 2.46 \\
3 & 456.55 & 486.27 & 6.51 & 464.40 & 1.72 \\
\hline
\end{tabular}

Note: $\varepsilon$ is the relative error of average tracer concentratior approach with respect to volumetric in $\%$

Table 5(a) shows comparison of flow rates $(Q)$ between breakthrough curves method and volumetric measurement and Table 5(b) shows comparison of flow rates $(Q)$ between average tracer concentration approach and volumetric measurement. Tables 5(a) and 5(b) show a very good agreement between calculated flow rates by either breakthrough curves method or average tracer concentration approach with volumetric flow rates. The relative errors of calculated flow rates with respect to volumetric flow rates generally $\leq 7 \%$ except at breakthrough curves method using tritium tracer of experiment-1 in which the error, $\varepsilon,>10 \%$. The relative high error at breakthrough curves method using tritium tracer of experiment- 1 may be caused of miss treatment of the samples before it was counted using liquid scintillation counter. It is observed that calculated flow rates based on average tracer concentration approach is relatively more accurate compared to calculated flow rates based on breakthrough curves method. This may due to the fact that in average tracer concentration approach, the interval of sample collection can be set as small as possible because only the mix of all samples that need to be analyzed as opposed to breakthrough curves method in which each individual sample needs to be analyzed. It is also observed from Table 4 that the relative errors based on tritium tracer are relatively higher compared to rhodamine WT tracer for both breakthrough curves method and average tracer concentration approach. This may be caused by error contribution from sample preparation (sample pre-treatment) that is needed for counting using liquid scintillation counter.

\section{Flow rate measurement in Mrican Irrigation Canal, Brantas river}

Based on the results of the accuracy tests that have been discussed in CALCULATION METHODS section and for practicality reasons, rhodamine WT was the only tracer used in the field study.

The natural rhodamine concentration in the flow that was measured before any experiment was in the range of 10 to $17 \mathrm{ppb}$. These natural concentrations were relatively high compared to natural rhodamine concentrations during accuracy tests that were conducted at laboratory. This phenomenon, however, is common because the presents of some products such as algae and tuffaceous limestone that can contribute to natural rhodamine concentration in the field. This background concentration was deducted from each measured concentration of sample. To check if there was a change of background concentration during the experiment, the natural background was also measured at the end of each experiment. In this study, however, the natural concentrations before and after experiment were no significantly different.

As explained in CALCULATION METHODS section that samples were collected at 2 sampling points to assure the consistency of the results. However, the difference of the measurements between the two sampling points was insignificant $(<2 \%)$. Based on this justification, the calculated flow rates for each case and for both 
canals were based on the data collected from the furthest sampling points and they were presented in Table 6 and the comparison of the flow rates based on average tracer concentration approach and measurement from constructed weir is given in Table 7.

Table 6. Calculated flow rate using average tracer concentration approach

\begin{tabular}{lcccccc}
\hline $\begin{array}{l}\text { Mrican } \\
\text { Canal }\end{array}$ & Case & $\begin{array}{c}\mathrm{V}_{0} \\
(l)\end{array}$ & $\begin{array}{c}C_{0} \\
(\mathrm{ppb}) \\
\times 10^{8}\end{array}$ & $\begin{array}{c}\bar{C} \\
(\mathrm{ppb})\end{array}$ & $\begin{array}{c}\text { Dura- } \\
\text { tion } \\
(\mathrm{sec})\end{array}$ & $\begin{array}{c}Q \\
\left(\mathrm{~m}^{3} / \mathrm{se}\right)\end{array}$ \\
\hline Right & 1 & 5.0 & 2.0 & 135.3 & 810 & 9.12 \\
Canal & 2 & 2.5 & 2.0 & 114 & 810 & 5.41 \\
& 3 & 1.0 & 2.0 & 64.6 & 630 & 4.91 \\
Left & 1 & 5.0 & 2.0 & 183.0 & 600 & 9.12 \\
Canal & 2 & 2.5 & 2.0 & 187.8 & 600 & 4.43 \\
& 3 & 1.0 & 2.0 & 169.2 & 540 & 2.19 \\
\hline
\end{tabular}

Table 7. Comparison of flow rates between average tracer concentration approach and weir

\begin{tabular}{lcccc}
\hline \multirow{2}{*}{ Location } & \multicolumn{3}{c}{ Flow rate $\left(\mathrm{m}^{3} / \mathrm{det}\right)$} \\
\cline { 3 - 4 } & Case & weir & $\begin{array}{c}\text { Average tracer } \\
\text { concentration approach }\end{array}$ & $\begin{array}{c}\varepsilon \\
(\%)\end{array}$ \\
\hline Mrican: Right & 1 & 8.52 & 9.12 & 6.58 \\
Canal & 2 & 4.32 & 5.41 & 20.15 \\
& 3 & 3.7 & 4.91 & 24.64 \\
Mrican: Left & 1 & 6.62 & 9.12 & 27.41 \\
Canal & 2 & 3.56 & 4.43 & 19.64 \\
& 3 & 2.44 & 2.19 & 11.42 \\
\hline
\end{tabular}

Note: $\varepsilon$ is the relative error of weir measurement with respect to average tracer concentration approach in \%

It can be seen from Table 7 that both flow measurements from weir and tracer methods are in satisfactory agreement. In general, measurements from existing weirs were below the measurement from the tracer method. While both of the measurements qualitatively can predict the flow but the relative errors of measurements from existing weir with respect to tracer method were found in the range of 6.48 to $27.41 \%$. Highest error was in case-1 of Left canal. However, based on the original design, both weirs at normal operation (case-1) would have conveyed the same amount of water. The fact that the flow measurement of both weir at flow case-1 were significantly different indicated that some problems have occurred to the weirs.

During the experiment, independent measurements were also conducted by the management of Brantas river and the comparison of the three measurements is given in Table 8 . While the current study was not intended to compare average tracer concentration approach and current meter, however, it is observed that all the measurements from existing weirs are below the measurements from current meters. This again agrees with the measurement of average tracer concentration approach. Based on these facts, the accuracy tests in laboratory, the consistency field measurements, average tracer concentration approach has shown to be a very good method for flow rate measurements and can be used to calibrate field flow rate measurement instruments such as weirs.

Table 8. Comparison of measured flow rates of three methods

\begin{tabular}{lccc}
\hline \multirow{2}{*}{ Location } & \multicolumn{3}{c}{ Flow rate $\left(\mathrm{m}^{3} / \mathrm{det}\right)$} \\
\cline { 2 - 4 } & Weir & $\begin{array}{c}\text { Average tracer concentration } \\
\text { approach }\end{array}$ & $\begin{array}{c}\text { Current } \\
\text { meter }\end{array}$ \\
\hline Mrican: & 8.52 & 9.12 & 11.98 \\
Right Canal & 4.32 & 5.41 & 6.93 \\
& 3.70 & 4.91 & 4.76 \\
Mrican: Left & 6.62 & 9.12 & 7.8 \\
Canal & 3.56 & 4.43 & 5.29 \\
& 2.44 & 2.19 & 2.23 \\
\hline
\end{tabular}

\section{CONCLUSION}

Based on the results found from accuracy test conducted at the Center of Isotopes and Radiation Applications Laboratory-BATAN and from field applications, the following are concluded:

From the accuracy test that was conducted at PAIR-BATAN laboratory, the tracer dilution methods, i.e., breakthrough curves method and average tracer concentration approach, were in very good agreement with volumetric measurements. Because the interval of sample collection can be set as small as possible without significant difficulties, in general, calculated flow rates based on average tracer concentration approach are relatively more accurate compared to calculated flow rates based on breakthrough curves method. Relative errors of flow rates based on tritium is relatively higher compared to rhodamine WT tracer for both breakthrough curves method and average tracer concentration approach may be due to complexity of sample preparation that is needed for counting using liquid scintillation counter.

Average tracer concentration approach has shown to be a very good method in measuring flow rates in open channels. From 3 cases of flow at 2 different irrigation canals, namely right and left Mrican irrigation canals, the calculated flow rates using average tracer concentration approach showed a satisfactory agreement between tracer method and existing weirs. The significant different between the two methods may be due to problems to the existing weirs.

From all 3 cases of flows at both right and left Mrican irrigation canals, the measurements 
from existing weirs were relatively lower than the measurements by either average tracer concentration approach or current meters. This implied that existing weirs need to be adjusted or repaired by the management of the Brantas river.

Based on accuracy tests conducted in laboratory, measurements consistency in the field, average tracer concentration approach can be utilized to calibrate constructed weirs and other field flow rate measuring devices.

\section{ACKNOWLEDGMENT}

The authors wish to thank the Authority of Brantas River Management (PT JASA TIRTA I) especially Mr. Masud and Mr. Dwi that have provided us useful technical information about Brantas river and existing weirs. This study is partly funded by PT JASA TIRTA I, Malang, East Java.

\section{REFERENCES}

1. G.I. Ezenne and C.C. Mbajiougu, Nigerian Journal of Technology 33 (2014) 192.

2. A. Tazioli, Hydrological Science Journal 56 (2011) 1314.

3. P. Sidauruk, A.H-D. Cheng and D. Ouazar, J. Ground Water 36 (1998) 208.

4. J. Jomba, D.M. Theuri, E. Mwenda et al., Int. J. of Engineering and App. Science 139 (2015) 21.

5. M.N. Kinyanjui, D.P. Tsombe, J.K. Kwanza et al., J. Agriculture, Science and Technology (JAGST) 13 (2011) 80.
6. M.TH. Van Genutchten, F.J. Leij, T.H. Skaggs et al., J. Hydrol. Hydromech. 61 (2013) 250 .

7. S. Lee, S. Chung and S. Park, J. Nuclear Science and Technology 44 (2007) 1467.

8. G. Axelsson, EPJ Web of conferences 50, 02001 (2013) 1.

9. C. Turnadge and B.D. Smerdon, J. Hydrology 519 (2014) 3674.

10. P. Sidauruk, J. Hidrosfir Indonesia 6 (2011) 97.

11. P. Jamin, P. Goderniaux, O. Bour et al., J. Contaminant Hydrology 182 (2015) 244.

12. F.M. Fan, A.S. Fleischmann, W. Collischonn, et al., J. Environmental Modelling \& Software 64 (2015) 58.

13. A. Aisopou, P.L. Bjerg, A.T. Sonne et al., J. Contaminant Hydrology 172 (2015) 71.

14. F. Eyrolle-Boyer, D. Claval, C. Cossonnet et al., J. Environmental Radioactivity 139 (2015) 24.

15. V. Cidzikienè, V.J.-Maselienè, R. Girgždienè et al., International J. Nuclear Energy 2014 (2014) 6, doi:10.1155/2014/201623.

16. M. Lepot, A. Momplot, G.L. Kouyi et al., J. Measurement and Instrumentation $\mathbf{4 0}$ (2014) 28.

17. E.C. Minor, E. James, J.A. Austin et al., Limnology and Oceanography 11 (2013) 631.

18. T. Guizerix and T. Florkowski, Guidebook on Nuclear Technique in Hydrology, IAEA Technical Report Series No. 91, Vienna (1983) 65. 